\title{
Afzetfinanciering en fiscus
}

\section{Mr. Ir. S. C. Santema}

\section{Inleiding}

In de marketingbenadering van industriële bedrijven is de laatste jaren een verschuiving te constateren van meer produktgerichte verkoopinspanningen naar activiteiten die zich richten op het aangaan en onderhouden van relaties. De veranderende marktomstandigheden hebben deze verschuiving versneld doen plaatsvinden. Het ontstaan van de 'business to business' benadering en de 'direct marketing' als vorm van marketing die zich richt op directe communicatie (Storm, 1987) zijn hiervan bekende voorbeelden. In de industriële marketing is het accent komen te liggen op het beheren van een portefeuille van relaties (V.d. Hart, 1985). Bij levering aan bedrijven is financiering een van de mogelijkheden voor het aangaan en onderhouden van - lange termijn - relaties. Tegenover deze veranderingen staat een fiscus die voor wat betreft de invordering van belastingen op een aantal punten niet wenst mee te veranderen. Met name het voorrangsrecht en het bodembeslag blijven in het ontwerp van de Invorderingswet 1989 grotendeels in de, uit 1845 stammende, vorm bestaan.

Zowel de fiscus als de aanbieder, die door middel van afzetfinanciering lange-termijnrelaties aangaat, hebben in de belastingplichtige die niet aan zijn verplichtingen kan voldoen een insolvente debiteur. De opstelling van de fiscus miskent de positie van de aanbieder. In dit artikel wordt deze stelling onderbouwd door de uitgangspositie van de fiscus steeds te vergelijken met de positie van de afzetfinancier. Daartoe komen achtereenvolgens afzetfinanciering, het voorrangsrecht van de fiscus en het fiscale bodembeslag aan de orde. Het artikel wordt afgesloten door een samenvatting.

Eventuele gevolgen van de invoering van het Nieuw Burgerlijk Wetboek zijn buiten beschouwing gelaten.

\section{Afzetfinanciering}

Afzetfinanciering is een vorm van commerciële dienstverlening, waarbij een producent of leverancier in eigen beheer financiering van zijn produkten aanbiedt als onderdeel van zijn marketing-mix (Santema, 1989). De financiering wordt daarmee een onderdeel van de relatie tussen aanbieder en afnemer.

In de huidige praktijk worden objectgebonden financieringen veelal tot stand gebracht door tussenkomst van een commerciële financieringsmaatschappij. De drie partijen gaan daarbij als het ware een driehoeksrelatie aan. De financieringsrelatie komt voor rekening van de financier, de technische relatie komt voor rekening van de producent of leverancier en de afnemer voldoet aan zijn betalingsverplichting door het betalen van de termijnen.

Bij afzetfinanciering ontstaat een tweepartijen relatie tussen producent en gebruiker. De financieringsinstelling stelt in deze figuur doelvermogens ter beschikking aan de producent ter financiering van het werkkapitaal.

Het volgende vereenvoudigde voorbeeld uit de autobranche geeft een nader inzicht in het verschil tussen een bekende vorm van objectfinanciering en afzetfinanciering.

Een gebruiker spreekt met een garagebedrijf af welk merk en type auto hij wenst te gebruiken. Tevens worden afspraken gemaakt over reparaties, onderhoud en gebruiksduur.

In de traditionele situatie neemt een leasemaatschappij het verkoopcontract van de garage over

Mr. Ir. S. C. Santema studeerde Bedrijfskunde aan de Technische Hogeschool te Eindhoven en Fiscaal Recht aan de Katholieke Hogeschool te Tilburg. Sinds 1 februari 1987 werkzaam in de business unit Agrochemicaliën van Shell Nederland Chemie, eerst in een bedrijfseconomische functie, later als manager algemene zaken in de Nederlandse verkooporganisatie. 


\section{MAB}

en financiert de koop voor de gebruiker. Indien de garage zelf de gebruiker de mogelijkheid van financiering aanbiedt, dan is sprake van afzetfinanciering. De leasemaatschappij volstaat dan met het ter beschikking stellen van voldoende kapitaal aan de garage. Alle relaties betreffende het produkt liggen nu tussen de garage en de gebruiker. In de leasingpraktijk zijn ontwikkelingen in deze richting waar te nemen.

Afzetfinanciering biedt een aantal voordelen. Een garage kent de marktrisico's van een auto beter dan een leasemaatschappij. Komt een auto terug bij de garage door het voortijdig beëindigen van het leasecontract, dan is de auto bij de garage couranter dan bij de leasemaatschappij. Voor de garage is het tevens een voordeel dat de relatie met de afnemer niet beïnvloed wordt door de relatie die de financieringsinstelling met dezelfde afnemer onderhoudt.

Het lange-termijnkarakter heeft als nadeel dat de garage afhankelijk wordt van de financiële ontwikkelingen van zijn afnemer. De garage heeft hierop geen wezenlijke invloed.

\section{Het voorrecht van de fiscus}

Artikel 22 lid 1 van het ontwerp van de Invorderingswet 1989 geeft het voorrecht van de fiscus weer: 's Rijks schatkist heeft wat de belastingen aangaat het recht van voorrang op al de roerende en onroerende goederen van de belastingschuldige. Lid twee geeft aan dat de voorrang niet geldt boven hypotheek en gerechtskosten bij uitwinning. In de Memorie van Toelichting staat te lezen dat de argumentatie uit 1845 (!) onverkort gehandhaafd blijft. Daarnaast wordt een aantal meer recente argumenten voor het handhaven van het voorrecht vermeld. De argumenten en de kritiek vanuit een afzetfinancierings-situatie luiden als volgt:

1 'De schatkist kiest haar debiteuren niet uit'.

$\mathrm{Bij}$ afzetfinanciering gaan producent en gebruiker een lange-termijn relatie aan waarbij de laatste de koopsom in een aantal termijnen voldoet, verdeeld over een aantal jaren. De producent heeft geen invloed op de wijze waarop een partner zich als debiteur ontwikkelt. Het toe- komstige betalingsgedrag is voor de leverancier even onzeker als voor de fiscus. Dit is bijvoorbeeld voor de Duitse 'Kommission für Insolvenzrecht' reden geweest voor te stellen de voorrechten van de fiscus te schrappen (Overeem, 1986).

2 '<Den last, die door allen getorscht, des te lichter gedragen wordt, moeten niet enkelen kwalijkgezinden straffeloos kunnen afwerpen>'.

Dit argument richt zich op de last die een bevolking draagt door het betalen van belasting. Een kwalijkgezinde belastingplichtige mag deze last niet van zich af kunnen werpen.

Indien de aandacht zich echter richt op een individuele belastingplichtige dan is diens insolventie een last die gezamenlijke schuldeisers dienen te dragen. Het is in deze situatie dat een specifieke schuldeiser niet deze gezamenlijke last straffeloos van zich af mag werpen. Artikel 1178 van het Burgerlijk Wetboek onderstreept deze zienswijze.

In plaats van een rechtvaardiging pro, is dit argument eigenlijk een pleit tegen het handhaven van het voorrecht.

3 'De schatkist moet met zekerheid op haar inkomsten kunnen rekenen'.

De inkomsten van de schatkist vormen een statistische grootheid. De inkomsten zijn met een bepaalde variantie verdeeld rond een gemiddelde. Binnen de variantie zijn de inkomsten van de schatkist 'zeker'.

Indien dit argument zich richt op de inkomsten per individuele belastingbetaler dan vallen twee zaken op:

- de omstandigheden van een belastingbetaler kunnen in de loop van het jaar wijzigen, waardoor de afgeleide belastingplicht verandert. Dit is per definitie niet zeker te noemen. Het is duidelijk dat de belastingbetaler in een dergelijk geval niets te verwijten valt;

- een leverancier van een gefinancierd bedrijfsmiddel moet ook met een bepaalde mate van zekerheid op zijn inkomsten kunnen rekenen teneinde de continuïteit van zijn bedrijf te kunnen waarborgen.

4 'Van de fiscus wordt een grotere lankmoedigheid verwacht dan van andere crediteuren. Bij 


\section{MAB}

gebreke van het voorrecht van de fiscus zou een scherpere aanslag- en invorderingspolitiek moeten worden gevoerd'.

Afzetfinanciering is een marketinginstrument dat zich richt op een lange-termijn relatie tussen leverancier en gebruiker. Deze lange-termijn doelstelling brengt voor de leverancier de noodzaak tot grote lankmoedigheid met zich mee. Marketing is immers het beheren van een portefeuille van relaties (zie inleiding). De commerciële noodzaak tot lankmoedigheid heeft de fiscus niet. Het idee dat lankmoedigheid slechts of in grotere mate van de fiscus verwacht wordt lijkt me dan ook een overschatting.

Het tweede gedeelte van het argument lijkt de echte reden te geven. Het voorrecht is een alternatief voor het voeren van een scherper aanslag- en invorderingsbeleid. Het gevolg hiervan is echter dat de belastingschuld door de verkeerde partij voldaan wordt. Het voeren van een scherper beleid maakt dat de fiscus, voor zover mogelijk, het geld ontvangt van de partij die de schuld heeft doen ontstaan. Een leverancier zal ook overgaan tot het voeren van een scherper debiteurenbeleid, wanneer hij vermoedt dat een vordering niet of moeilijk voldaan zal worden.

5 'De overheid is verplicht tot kredietverlening, andere debiteuren niet. Dit geldt met name voor belastingen waarbij inning niet gelijk mogelijk is met het genieten van inkomen'. Allereerst valt op dat hier waarschijnlijk 'crediteuren' bedoeld is in plaats van 'debiteuren'. (NB de tekst is letterlijk uit de toelichting van het ontwerp overgenomen.)

Het is de concurrentiepositie die de leverancier dwingt financieringsvormen aan te bieden. Is hij niet bereid tot het verlenen van krediet, dan loopt hij het risico de order te missen. Hierdoor ontstaat als het ware een 'plicht'. Bovendien is het de overheid zelf die gekozen heeft voor het achteraf innen van belastingen. In een dergelijk geval spreken van kredietverlening lijkt dan ook niet op zijn plaats. Uitstel van inning van een schuld is materieel misschien wel hetzelfde als kredietverlening, formeel is het dat zeker niet.
6 'Sommige belastingschulden betreffen in wezen voor de staat geïnde nog niet afgedragen gelden....'

Een vergelijkbare situatie zou ontstaan indien een leverancier een boekhoudkantoor inschakelt voor het innen van de afzetfinancieringstermijnen. In dat geval ontvangt het boekhoudkantoor af te dragen gelden. Het is de overheid zelf die gekozen heeft voor het door anderen laten innen van de belastingen. Daarvan dient ze dan ook zelf de consequenties te dragen, en deze niet af te wentelen op andere partijen op dezelfde markt.

7 'De fiscus kan in tegenstelling tot andere crediteuren niet vooraf zekerheid bedingen, zoals bijvoorbeeld eigendomsvoorbehoud. ....'

In het geval van afzetfinanciering heeft de leverancier weliswaar het juridische eigendom van een in gebruik afgestaan bedrijfsmiddel, maar dat brengt niet met zich mee dat de vorderingen die uit dit gebruik voortgevloeid zijn met zekerheid geïnd kunnen worden. Het juridische eigendom geeft de leverancier alleen de mogelijkheid de machine op een gegeven moment terug te nemen. De waardevermindering (en de overige derving aan inkomsten) tot dat moment kan de leverancier daarmee niet terugkrijgen. Op het moment dat een bedriifsmiddel gebruikt is, is de verhaalspositie van de leverancier op het gebruikte gedeelte verdwenen. In de argumentatie heeft de fiscale wetgever blijkbaar het verschil tussen juridische eigendom (waarop bijvoorbeeld eigendomsvoorbehoud is gericht) en economische eigendom door elkaar gehaald.

In het bovenstaande is geen melding gemaakt van de ijzersterke positie die de tweede Anti-misbruikwet bij omzet- en loonbelasting (de zogenaamde bestuurdersaansprakelijkheid) verschaft aan de overheid. Door deze regeling dient een in betalingsmoeilijkheden verkerend bedrijf immers te melden dat er problemen zijn (Wessels, 1986). Blijft de melding achterwege dan kan de ondernemer persoonlijk aansprakelijk worden gesteld. Voor een leverancier is het veel moeilijker de bestuurder of eigenaar van een rechtspersoon aan te spreken voor het ontstaan van een schuld. 


\section{MAB}

De Memorie van Toelichting vervolgt nog met de mededeling dat een 'bezinning ten principale over het voorrecht van de fiscus' op zijn plaats zou zijn. Dit is bij het maken van het ontwerp niet gebeurd om de bestaande rechtspraktijk, ontstaan door de oude wet, de jurisprudentie en de uitvoeringsbesluiten voort te laten bestaan.

Het is hoopgevend dat dezelfde Memorie van Toelichting op een andere plaats melding maakt van de oprichting van een werkgroep met als opdracht: 'alle aspecten van het fiscale voorrecht en bodemrecht in beeld te brengen, om zodoende omtrent de handhaving in enigerlei vorm, cq. de afschaffing een afweging te kunnen maken'. Het is te hopen dat de werkgroep het voorkeursrecht van de fiscus op zijn juiste waarde weet te schatten. Het verschil (of de overeenkomst ?) tussen de overheid en de afzetfinancieringspraktijk zal dan beter tot zijn recht komen.

\section{Conclusie}

De redenen die de fiscus aanvoert als argumentatie voor het recht van voorrang gelden in dezelfde mate voor de producent of leverancier die gebruik maakt van het marketinginstrument afzetfinanciering. De overheid had de herziening van de invorderingswet moeten aangrijpen om haar positie ten opzichte van nieuwe structuren in de markt te bepalen. Nu dit niet is gebeurd, dient de overheid zich te realiseren dat voor het recht van voorrang geen reële argumentatie voorhanden is.

\section{Fiscaal bodembeslag}

In artikel 23 van het ontwerp van de Invorderingswet 1989 wordt het fiscale beslag geregeld. Voor de tekst wordt naar het ontwerp verwezen. De tekst van het eerste en het tweede lid is praktisch gelijk aan het eerste en het tweede lid van artikel 16 van de Invorderingswet 1845 . In de toelichting staat dat een materiële wijziging niet beoogd is. In het derde lid is een bijzonder verhaalsrecht neergelegd, beter bekend als het fiscale bodemrecht. In dit lid is de bewoording uit 1845 voor wat betreft de bodem en de goederen gehandhaafd. Dit is gedaan om de 'jarenlange praktijk' inzake deze bepaling te kunnen handhaven. De toelichting beschrijft vervolgens dat het feitelijk gebruik van de bodem van belang is voor de vaststelling of op de goederen die zich op een bodem bevinden beslag gelegd kan worden. Het is daarbij niet vereist dat de gebruiker met uitsluiting van ieder ander recht heeft op de bodem. Letterlijk staat er: 'Het is niet relevant wie de eigenaar van het perceel is of wie dat perceel heeft gehuurd. Beslissend is uitsluitend de feitelijke verhouding van de belastingschuldige tot het perceel waarin of waarop de in beslag genomen goederen zich bevinden'. Deze toelichting geeft aan dat de wetgever wel degelijk afwijkt van de bestaande jurisprudentie. Bijvoorbeeld HR 12 april 1985, RvdW $1985 \mathrm{nr} .4$, waarin huur de fiscus de mogelijkheid tot verkoop van beslagen goederen ontnam. Huur wordt nu in de toelichting als een niet relevante belemmering voor verkoop van de goederen terzijde geschoven.

Alles overziend komt de herziene regeling neer op een uitbreiding van de regeling uit 1845 . De wetgever pakt alle mogelijkheden aan om verhaal mogelijk te maken en houdt daarbij totaal geen rekening met de belangen van de overige schuldeisers of met veranderingen in onze maatschappij. Geppaart (1985) ziet in deze ontwikkeling een argumentatie voor zijn stelling dat het tijd wordt voor een modernisering van het bodembeslag.

Bij afzetfinanciering is de leverancier ertoe overgegaan bijvoorbeeld een machine in een aantal gedeelten ter beschikking te stellen aan een gebruiker. Elk gedeelte komt overeen met een jaarcapaciteit. De gebruiker benut de jaarcapaciteit van de machine en fabriceert daarmee een jaarproduktie. De jaarcapaciteit is voor hem een nutseenheid. In deze zienswijze bestaat een machine uit een voorraad nutseenheden (Santema, 1987). De nog niet gebruikte eenheden zijn nog niet verkocht en behoren derhalve aan de producent/leverancier in eigendom. In analogie met de wijze waarop niet gebruikte voorraden in de wet (en het wetsvoorstel) behandeld worden, is het onduidelijk waarom de resterende nutseenheden van de machine onder het bodembeslag vallen.

Economisch gezien heeft het beslagrecht van de fiscus ook geen waarde. Veelal zal de fiscus, vanwege het gebrek aan kennis van de markt, bij ver- 


\section{MAB}

koop slechts de schrootwaarde van een machine kunnen realiseren. Voor een leverancier die gebruik maakt van afzetfinanciering, betekent de verkoop een afwaardering van de op zijn balans vermelde boekwaarde van de machine. Daarnaast verstoort een dergelijke verkoop het waardeverloop in de markt. Voor een willekeurige gebruiker lijkt het erop dat de restwaarde in de markt gelijk is aan de schrootwaarde. Dit kan een afwaardering betekenen, omdat de marktwaarde lager geworden is dan de waarde volgens het fiscale afschrijvingsschema. De verkoop kan derhalve een reeks van afwaarderingen tot gevolg hebben met de fiscale gevolgen van dien. In de markt voor industriële koffiezetmachines heeft zich een dergelijke ontwikkeling voorgedaan.

Indien de fiscus het instrument afzetfinanciering op zijn juiste waarde weet te schatten en zich realiseert wat de verhaalspositie inhoudt, dan zal beslaglegging op en verkoop van gefinancierde produktiemiddelen tot het verleden behoren. De leverancier van het produktiemiddel zal ingeval van insolventie van de debiteur de machine terugnemen en in een nieuw contract ter beschikking stellen aan een nieuwe gebruiker. Zijn kennis van de markt van de machine brengt deze mogelijkheid met zich mee. Het is een feit dat de fiscus hierdoor het - lage - bedrag bij verkoop misloopt. De overige effecten die ontstaan door de afwaarderingen blijven echter ook achterwege. Tegenover een 'verlies' bij de wanbetalende belastingplichtige staat een continuïteit van de overige marktpartijen en de daarvan afgeleide belastinginkomsten.

In het arrest HR 9 januari 1981 (nr. 11636, RvdW $n r .14,1981$ ) vestigde de eigenaar van een verhuurd computersysteem de aandacht op de 'vernietiging van economische waarde'. De Hoge Raad verwierp dit beroep met de volgende bewoordingen: ' ...., die uit hoofde van haar bedrijf computersystemen verhuurt aan derden, behoort het risico van uitwinning van die goederen wegens belastingschulden van haar huurders te dragen'. De Hoge Raad stelt vervolgens: 'Zij kan voorts ingeval van uitwinning haar schade beperken door zelf haar eigen computer te kopen.....' Met andere woorden is het aan de crediteur om aan de, door de fiscus geschapen, situatie van vernietiging van economische waarde een einde te maken.

In de Memorie van Antwoord bij het ontwerp van de Invorderingswet 1989 is te lezen dat de wetgever inziet dat het beslag dat gelegd is op onbetaalde goederen, die op grond van artikel 230 Wetboek van Koophandel worden teruggevorderd, opgeheven dient te worden. In geval van afzetfinanciering dient de fiscus op gelijke gronden het beslag op te heffen, wanneer de leverancier de machine terugvordert. De machine is immers een voorraad, nog niet betaalde, nutseenheden, welke in eigendom toebehoren aan de leverancier. Omdat de Memorie verschenen is na vorenstaand arrest valt het te bezien of de Hoge Raad in deze tijd een soortgelijke uitspraak zou doen.

\section{Conclusie}

Het fiscale bodembeslag geeft de fiscus een verhaalspositie op goederen van derden. Afzetfinanciering is economisch te zien als verkoop van nutseenheden. In de machine is steeds een voorraad nutseenheden aanwezig, welke gelijk is aan de capaciteit voor volgende jaren. Deze nutseenheden zijn eigendom van de leverancier. In de parallel met andere voorraden dient een in afzetfinanciering ter beschikking gestelde machine buiten de werking van het fiscale bodembeslag te blijven.

\section{Samenvatting}

Afzetfinanciering is een nieuw marketing-instrument waarbij een leverancier van een produktiemiddel zijn afnemer in de gelegenheid stelt de in een machine aanwezige produktiecapaciteit per tijdseenheid af te nemen. De gebruiker krijgt een machine ter beschikking en betaalt daarvoor een zekere vergoeding. De machine is als zodanig aanwezig op het grondgebied van de gebruiker en dient ter 'stoffering' in de zin van het fiscale bodembeslag. Dit brengt met zich mee dat de fiscus een voorkeur heeft boven de eigenaar van de machine ingeval de gebruiker niet in staat is aan zijn verplichtingen te voldoen. De argumentatie 
die de wetgever bij dit voorrecht geeft is niet toereikend om het voorrecht te handhaven ingeval van afzetfinanciering. De werkgroep, genoemd in de Memorie van Toelichting bij het ontwerp van de Invorderingswet 1989, geeft de praktijk de hoop dat bijzondere structuren als afzetfinanciering op hun waarde geschat zullen gaan worden. Economisch gezien blijkt het fiscale bodembeslag en de daarbij behorende uitwinning niet de optimale resultaten op te leveren voor zowel de fiscus als de praktijk. Het lijkt daarom raadzaam om aan de hand van financiële gegevens, zoals het budgettaire belang voor de overheid, de gevolgen voor de industrie, de afgeleide gevolgen voor de af te dragen belastingen en de gevolgen voor de werkgelegenheid, te beoordelen hoe sterk het bodembeslag dient te zijn.

Het spreekwoord 'schoenmaker blijf bij je leest' waarschuwt reeds lang voor het ontwikkelen van activiteiten die niet op de lijn van de eigen activiteiten liggen. Het verkopen van niet aan de belastingschuldige toebehorende goederen valt buiten de leest van de fiscus, het voeren van een stringent aanslag- en invorderingsbeleid behoort daarentegen wel tot de kernactiviteiten. Hierin dient dan ook de oplossing gezocht te worden voor de problemen die zullen ontstaan zijn door het afschaffen van het voorrecht en het bodembeslag.

\section{Literatuur}

Geppaart, Prof. Mr. Ch. P. A., pre-advies Nederlandse Juristenvereniging 1986, Tjeenk Willink, Zwolle.

Hart, Prof. Dr. H. W. C. v.d., Leveren aan bedrijven, inaugurale rede, 19 april 1985.

Memorie van Antwoord, Invorderingswet 1989, vergaderjaar 1988-1989.

Overeem, Mr. R., Bodemrecht in beweging, artikel in MBB, no. 6 , juni 1986.

Santema, Mr. Ir. S. C., Leasing en Investeringsstimulering in internationaal perspectief, eigen beheer, Rotterdam, 1987.

Santema, Mr. Ir. S. C., Afzetfinanciering als marketinginstrument, artikel in Tijdschrift voor Marketing, september 1989.

Storm, Prof. Dr. C. M., Competitie en competentie: van vier P's naar drie R's, artikel uit Harvard Holland Review, no. 12 herfst 1987.

Wessels, Mr. B., Fiscaal bodemrecht ondanks kritiek niet op de helling, artikel in de rubriek Onderneming en fiscus in FEM, 26 juni 1986.

Wetsvoorstel, Invorderingswet 1989, vergaderjaar 1987-1988, voorstel van wet en Memorie van Toelichting. 